\title{
The Location and Frequency of Intestinal Metaplasia at the Esophagogastric Junction in 223 Consecutive Autopsies: Implications for Patient Treatment and Preventive Strategies in Barrett's Esophagus
}

\author{
Adrian H. Ormsby, MBChB, Sony P. Kilgore, M.D., John R. Goldblum, M.D., Joel E. Richter, M.D., \\ Thomas W. Rice, M.D., Terry L. Gramlich, M.D. \\ Center for Swallowing and Esophageal Disorders and the Departments of Anatomic Pathology (AHO, SPK, \\ JRG, TLG), Gastroenterology (JER), and Thoracic and Cardiovascular Surgery (TWR), The Cleveland Clinic \\ Foundation, Cleveland, Ohio
}

The frequency of intestinal metaplasia at the esophagogastric junction is as high as $36 \%$ in endoscopy studies; the majority of cases (approximately 67\%) occur in short segments of esophageal columnar mucosa. The validity of these studies has been questioned, however, because of heterogenous underlying diseases prompting endoscopy. To determine the frequency and origin of intestinal metaplasia at the esophagogastric junction, we histologically evaluated the entire esophagogastric junction for the presence of intestinal metaplasia using Alcian blue/periodic acid-Schiff mucin stains in 223 consecutive autopsies. Precise localization of the $\mathrm{Z}$ line in relation to the esophagogastric junction and tongues of esophageal columnar-appearing mucosa were noted in each case. Mean patient age was 47 years; $69 \%$ of patients were male, and $63 \%$ were white. Twenty five of 223 cases (11\%) had intestinal metaplasia at the esophagogastric junction. Only 2 of 25 cases $(8 \%)$ had intestinal metaplasia in the esophagus; the remaining 23 cases (92\%) had intestinal metaplasia in the gastric cardia. Male gender, advanced age, white ethnic origin, and short tongues of esophageal columnar mucosa were not associated with gastric cardia intestinal metaplasia. An association of distal gastric intestinal metaplasia $(P<.01)$ and chronic gastritis $(P<.01)$ with gastric cardia intestinal metaplasia suggests a role for $\mathrm{Hel}$ icobacter pylori infection in this process. The frequency of intestinal metaplasia at the esophagogastric junction in an unselected autopsy population is low (11\%) even after exhaustive histologic evalua-

Copyright (C) 2000 by The United States and Canadian Academy of Pathology, Inc.

VOL. 13, NO. 6, P. 614, 2000 Printed in the U.S.A.

Date of acceptance: December 20, 1999.

Address reprint requests to: Terry L. Gramlich, M.D., Department of Anatomic Pathology, L25, The Cleveland Clinic Foundation, 9500 Euclid Avenue, Cleveland, OH 44195. tion using Alcian blue mucin stains. Furthermore, intestinal metaplasia is confined to the gastric cardia in more than $90 \%$ of cases with no association to male gender, white ethnic origin, advanced age, or the presence of short segments of esophageal columnar-appearing mucosa at endoscopy. These results demonstrate that caution is warranted when applying the findings of endoscopy studies to the development of preventive and screening strategies aimed at identifying Barrett's esophagus in an asymptomatic general population.

KEY WORDS: Barrett's esophagus, Gastric cardia, Helicobacter pylori, Intestinal metaplasia.

Mod Pathol 2000;13(6):614-620

The presence of intestinal metaplasia in the tubular esophagus has important clinical implications because of its association with the development of esophageal dysplasia and subsequent adenocarcinoma (1-3). Recent studies, however, have showed that intestinal metaplasia in the proximal stomach has a very low risk for the development of dysplasia or adenocarcinoma (4-12). Therefore, determining the origin of intestinal metaplasia at the esophagogastric junction-that is, esophagus versus stomach-is critical in the assessment of cancer risk and patient treatment.

In 1994, a study by Spechler et al. (5) showed for the first time that intestinal metaplasia at the esophagogastric junction, demonstrated in either short segments of columnar mucosa or at a normalappearing $\mathrm{Z}$ line, was present in a high proportion of patients (18\%) who presented at a general endoscopy unit. Since that time, numerous studies have demonstrated similar findings, with up to $36 \%$ of patients in general endoscopy units demonstrating intestinal metaplasia at the esophagogastric junction $(6-12)$. Some have raised the possibility that 
the high frequency of intestinal metaplasia found at the esophagogastric junction in endoscopy studies is a phenomenon that applies to an asymptomatic general population.

If one were to assume that all of these patients had intestinal metaplasia in the esophagus, then these patients would be classified as having Barrett's esophagus with the attendant risk of dysplasia and carcinoma. There is, however, a large disparity between the high frequency of intestinal metaplasia at the esophagogastric junction in endoscopy studies and the relatively low rate of esophageal adenocarcinoma estimated at 2 to 4 per 100,000 in the United States (13).

It is desirable, therefore, to evaluate a population without underlying foregut disease and with a gender, age, and ethnic distribution similar to that of the general population. Moreover, accurate localization and comprehensive histologic examination of the entire esophagogastric junction would be helpful, given the difficulties of precisely identifying the esophagogastric junction at endoscopy and the limited sampling that can be achieved using endoscopic biopsy specimens. To this end, we histologically evaluated the entire esophagogastric junction in 223 consecutive forensic autopsies.

\section{MATERIALS AND METHODS}

\section{Case Selection and Tissue Specimen Evaluation}

Consecutive esophagogastrectomy specimens from pediatric and adult forensic autopsies obtained between August 1997 and February 1998 were evaluated. In all cases, information related to surgeries, prescription drug usage, patient age, gender, and ethnic origin was obtained from review of the available medical records after the patients' death.

Upon gross examination of the fresh specimen, the precise location of the squamocolumnar junction ( $\mathrm{Z}$ line) and its relationship to the esophagogastric junction, as defined by the peritoneal reflection and the proximal margin of the gastric folds, the region at the esophagogastric junction where splaying of the gastric folds is first encountered, was noted by two observers. In addition, the presence and length of segments of columnar-appearing mucosa in the tubular esophagus were noted at gross inspection. The entire esophagogastric junction and all areas of columnar-appearing mucosa in the tubular esophagus were sectioned longitudinally and fixed in $10 \%$ neutral buffered formalin. Sections of the esophagogastric junction were taken such that the majority of the section (approximately $3.5 \mathrm{~cm}$ ) was composed of gastric mucosa with approximately $0.5 \mathrm{~cm}$ of esophageal squamous mucosa. In addition, a representative section of the distal stomach was obtained from each specimen for histologic evaluation. Because of formalin fixation, an estimated $10 \%$ shrinkage of the esophagus and proximal stomach was encountered. In each case, $5-\mu$ sections were stained with hematoxylin and eosin as well as Alcian blue/periodic acidSchiff ( $\mathrm{pH}$ 2.5). To minimize autolysis, only cases in which less than $24 \mathrm{~h}$ elapsed between patient death and time to fixation of the specimen were included for evaluation.

\section{Histologic Evaluation}

All slides were evaluated in a blinded fashion by two observers who were looking for the presence of intestinal metaplasia (unequivocal Alcian bluepositive goblet cells) and epithelial dysplasia. Goblet cells were readily distinguishable from so-called "columnar blue" cells because of their demonstration of cytoplasmic distension with a goblet-like morphology having a flattened nucleus immediately adjacent to the epithelial basement membrane. In contrast, "columnar blue" cells showed minimal cytoplasmic distension, lacked a flattened nucleus, and demonstrated Alcian blue reactivity generally at the most apical portion of the cytoplasm immediately adjacent to the luminal aspect of the cell. The presence of chronic gastritis, using the guidelines of the Sydney System (14), was noted in all sections from the distal stomach. Because of the strong association of intestinal metaplasia and chronic gastritis in the distal stomach with Helicobacter pylori colonization (15), demonstration of these histologic features was used as a surrogate marker for the presence of $H$. pylori infection.

Because of only limited sampling of squamous mucosa at the esophagogastric junction, no attempt to systematically evaluate the esophageal squamous mucosa was made. Moreover, because the aim of the study was to determine specifically the extent of intestinal metaplasia present at the esophagogastric junction, it was believed that evaluation of squamous esophageal mucosa was beyond the scope of the present study.

\section{Statistical Analysis}

Between-group comparisons were undertaken using Fisher's exact (two-sided) and $\chi^{2}$ tests.

\section{RESULTS}

Overall, 223 pediatric and adult autopsies were evaluated. The mean patient age was 47 years (range, 0 to 93 years); $8 \%$ of patients were younger than 18 years, $69 \%$ were male, and $37 \%$ were nonCaucasian. Because of strict adherence to the time between patient death and specimen fixation $(<24$ 
h), autolysis was minimized and was not an issue in the gross and histologic evaluation of the gastroesophageal specimens. In all cases, the location of the proximal gastric folds coincided with the most proximal extent of the gastric peritoneal reflection.

At gross inspection, tongues of columnarappearing mucosa located in the distal esophagus were noted in 18 of $223(8 \%)$ cases, all of which were less than $3 \mathrm{~cm}$. In 2 of these 18 cases (11\%), intestinal metaplasia was identified in the tubular esophagus on subsequent histologic evaluation and were classified as Barrett's esophagus. The tongues of columnar-appearing mucosa in these two cases measured $2.2 \mathrm{~cm}$ and $1.8 \mathrm{~cm}$, respectively. In both cases, a high density of Alcian blue-positive goblet cells involving the entire length of the grossly identified tongue of esophageal columnar mucosa was present on histologic evaluation (Figs. 1 and 2). In addition, periodic acid-Schiff-positive mucussecreting glands in a lobular configuration reminiscent of gastric cardiac-type mucosa were not observed. The two patients were a white male and female, aged 66 and 52 years, respectively, and in both cases, no chronic gastritis, distal stomach intestinal metaplasia, or epithelial dysplasia was identified and neither patient had a history of using prescribed acid-suppressing medications. Perfect agreement between the two observers as to the presence of unequivocal Alcian blue-positive goblet cells was reached in both cases.

In the remaining 16 cases with tongues of esophageal columnar mucosa identified on gross examination, only erosion of squamous epithelium was identified on evaluation of histologic sections from these areas. Intestinal metaplasia was not identified. In only 1 of these 16 cases (6\%) was intestinal metaplasia identified in the gastric cardia on histologic evaluation. The location of the intestinal metaplasia in the gastric cardia in this case was

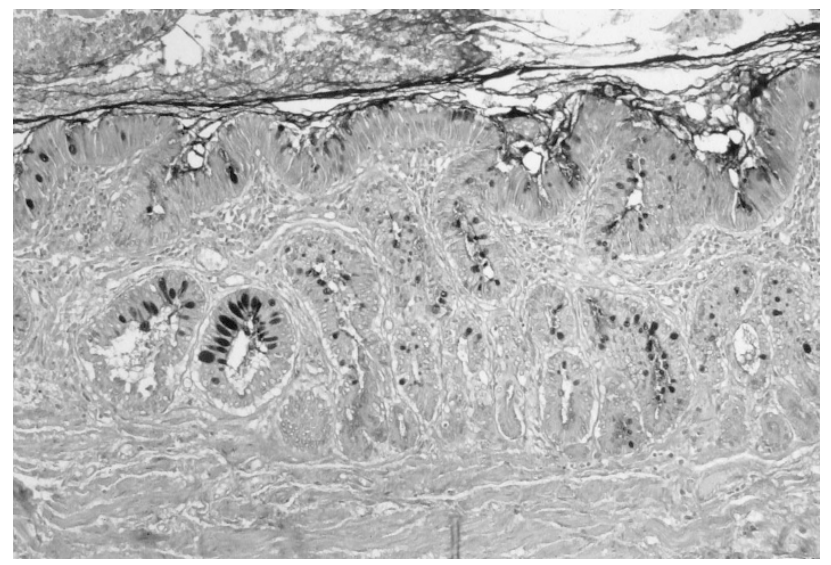

FIGURE 1. Low-power magnification of esophageal intestinal metaplasia showing Alcian blue-positive goblet cells involving the entire length of the esophageal columnar mucosa (Alcian blue/periodic acid-Schiff $\mathrm{pH} 2.5$ ).

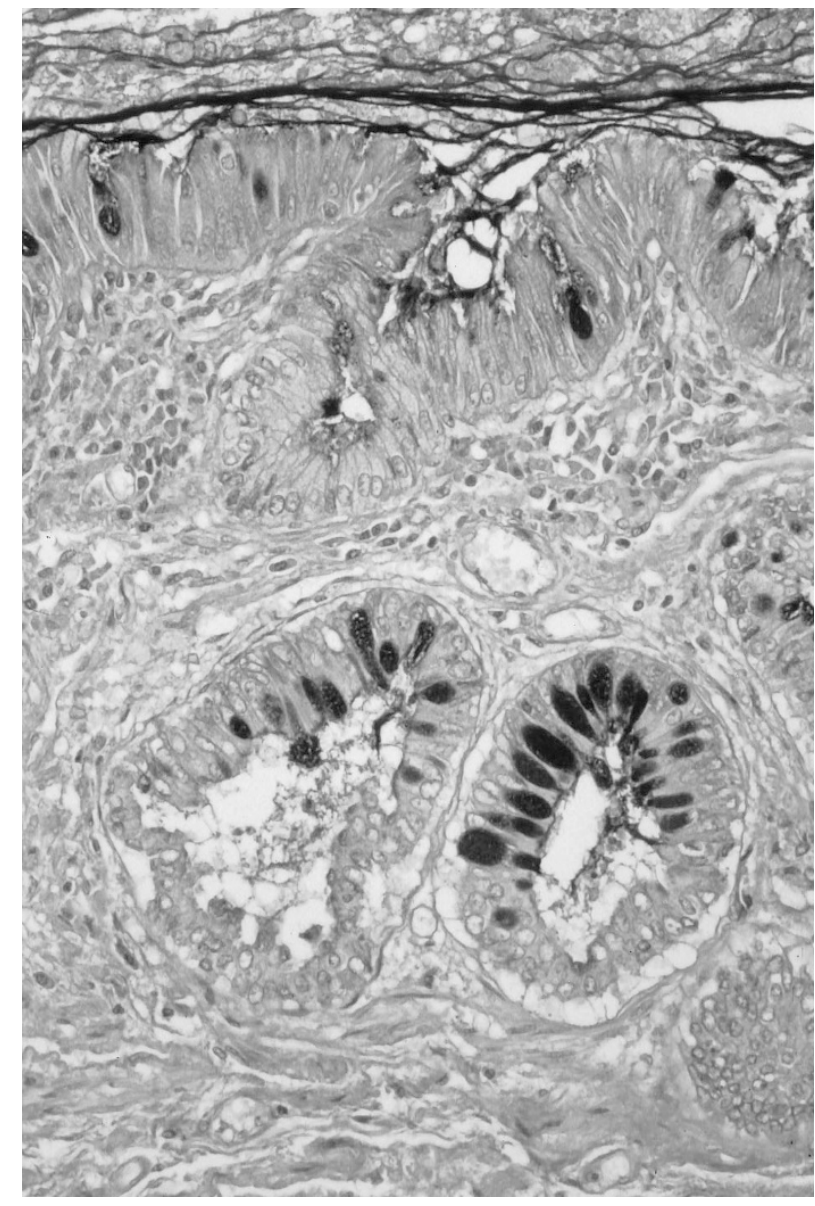

FIGURE 2. High-power magnification of esophageal intestinal metaplasia showing a high density of Alcian blue acid mucin-positive goblet cells (Alcian blue/periodic acid-Schiff pH 2.5).

verified on both gross and microscopic examination. That is, intestinal metaplasia was present in histologic sections taken immediately distal to the proximal gastric folds and peritoneal reflection as identified on gross inspection, and on microscopic evaluation, the intestinal metaplasia was present within periodic acid-Schiff-positive mucussecreting glands in a lobular configuration resembling gastric cardiac mucosa, immediately distal to recognizable squamous epithelium corresponding to the grossly identifiable squamocolumnar junction.

In 22 of 223 cases $(9.9 \%)$, intestinal metaplasia was present immediately distal to a normalappearing squamocolumnar junction located immediately distal to the proximal gastric folds and peritoneal reflection. The microscopic appearance as demonstrated in esophagogastric junction histologic sections supported the gross impression of gastric cardia intestinal metaplasia, as evidenced by the presence of Alcian blue-positive goblet cells within periodic acid-Schiff-positive mucinsecreting glands in a lobular configuration immediately distal to squamous esophageal mucosa (Figs. 3 and 4). The goblet cells in the gastric cardia 


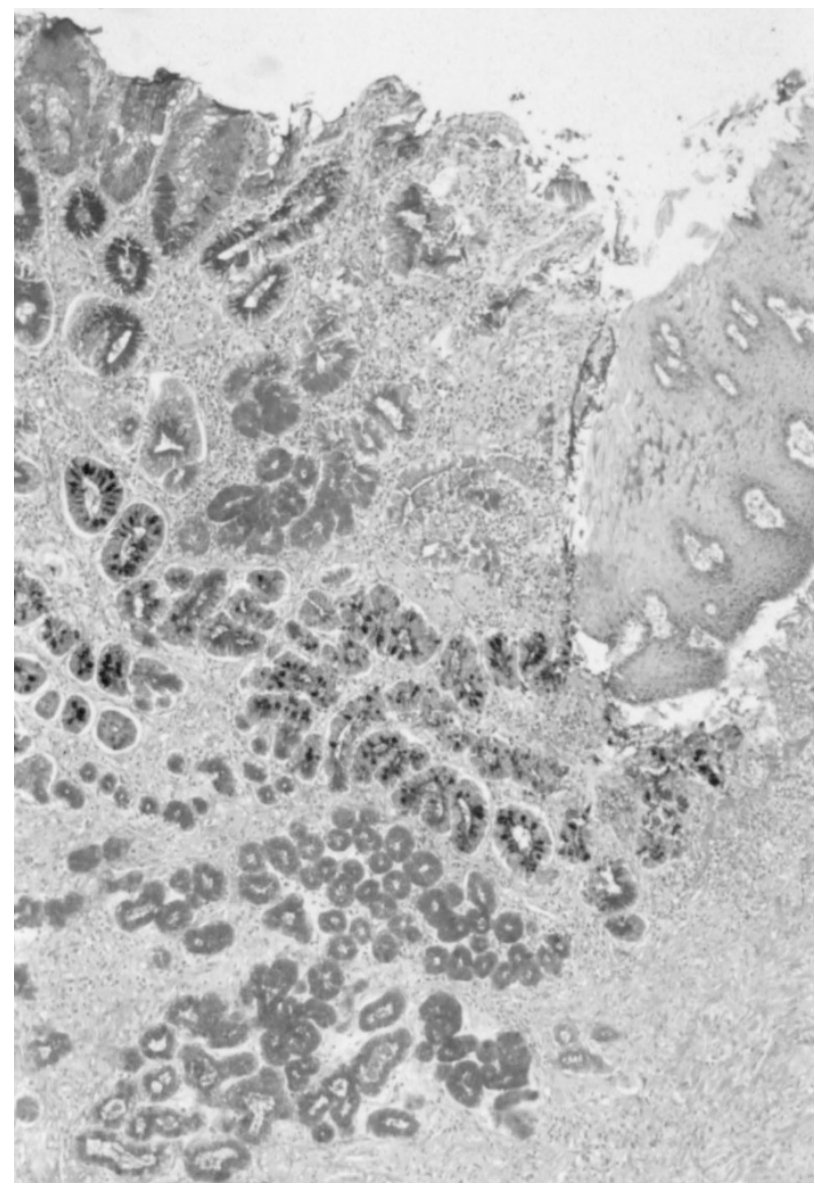

FIGURE 3. Low-power magnification of gastric cardia intestinal metaplasia showing Alcian blue-positive goblet cells within periodic acid-Schiff-positive neutral mucin-secreting cardiac glands in a lobular configuration immediately distal to esophageal squamous mucosa (Alcian blue/periodic acid-Schiff $\mathrm{pH} 2.5$ ).

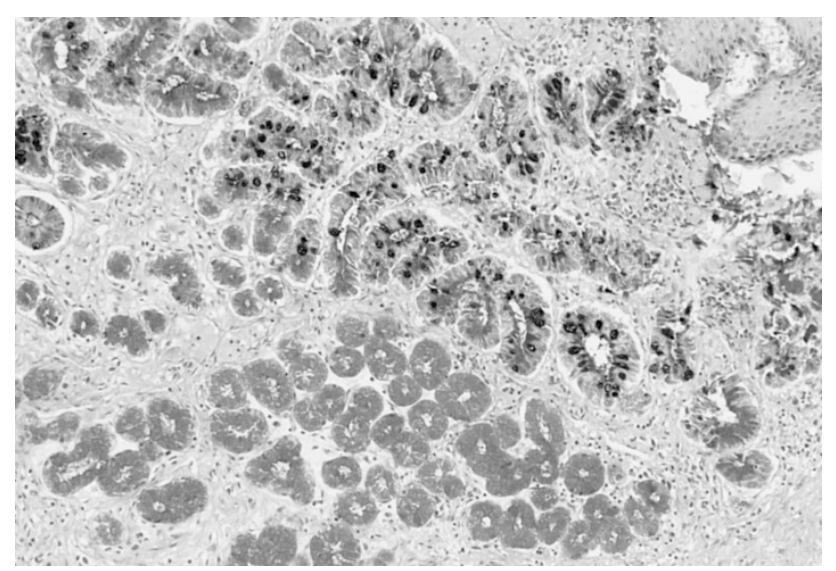

FIGURE 4. High-power magnification of gastric cardia intestinal metaplasia with Alcian blue acid mucin-positive goblet cells within periodic acid-Schiff-positive neutral mucin-secreting cardiac glands (Alcian blue/periodic acid-Schiff $\mathrm{pH} 2.5$ ).

usually involved the deep cardiac glands, often in a patchy distribution; however, surface glandular involvement also was observed. Unlike the two cases of Barrett's esophagus, the gastric cardia intestinal metaplasia measured less than $3 \mathrm{~mm}$ in maximum length in all 23 cases. Perfect agreement between the two observers as to the presence of unequivocal Alcian blue-positive goblet cells was reached in all 23 cases of gastric cardia intestinal metaplasia.

In summary, a total 23 of 223 cases $(10.3 \%)$ had gastric cardia intestinal metaplasia. Twenty-two of 23 cases $(95 \%)$ had gastric cardia intestinal metaplasia immediately distal to a normal-appearing squamocolumnar junction, and only 1 of 23 cases (4.3\%) had gastric cardia intestinal metaplasia with a coexisting tongue of columnar-appearing mucosa, which on subsequent histologic evaluation demonstrated eroded squamous epithelium without intestinal metaplasia or gastric cardiac-type or gastric fundic-type mucosa.

A comparison of patients who had intestinal metaplasia of the gastric cardia $(n=23)$ and those who did not intestinal metaplasia $(n=198)$ showed no significant differences with respect to age, gender, ethnic origin, or the presence of columnarappearing mucosa at the esophagogastric junction (see Table 1). However, patients who had intestinal metaplasia of the cardia were significantly more likely to have chronic gastritis and intestinal metaplasia in the distal stomach (Fig. 5), suggesting chronic H. pylori infection, compared with those who did not have intestinal metaplasia of the cardia (see Table 1). Epithelial dysplasia was not identified in any case of gastric cardia intestinal metaplasia.

\section{DISCUSSION}

The association of intestinal metaplasia in long segments of esophageal columnar mucosa with esophageal dysplasia and adenocarcinoma was first recognized more than 20 years ago (16-21) and is now a widely recognized and accepted relationship $(1,8)$. Only recently, however, has intestinal metaplasia in short segments of columnar mucosa been studied in any detail, being largely ignored until the study by Spechler et al. in 1994 (5). This study showed that intestinal metaplasia at the esophagogastric junction occurred in $18 \%$ of patients who presented to a general endoscopy unit. Approximately two thirds of these cases were in patients who had short segments of esophageal columnar mucosa (i.e., short-segment Barrett's esophagus); the remainder occurred at a normal-appearing $\mathrm{Z}$ line. Numerous subsequent studies have confirmed the high frequency of intestinal metaplasia at the esophagogastric junction (6-12). Further research, including prospective studies with long patient follow-up periods, have demonstrated that patients who have intestinal metaplasia in short segments of esophageal columnar mucosa also are at increased risk for developing dysplasia and adenocarcinoma (22-24). Recent studies have shown, however, that 
TABLE 1. Demographic and Histologic Comparison of Patients with and without Gastric Cardia Intestinal Metaplasia

\begin{tabular}{|c|c|c|c|c|c|c|c|}
\hline & No. & Male (\%) & White (\%) & $>50$ y (\%) & $\begin{array}{c}\text { Distal } \\
\text { Gastritis } \\
(\%)\end{array}$ & $\begin{array}{c}\text { Distal } \\
\text { IM (\%) }\end{array}$ & $\begin{array}{c}\text { Mucosal } \\
\text { Tongues } \\
\text { (\%) }\end{array}$ \\
\hline CIM (\%) & 23 & $19(83)$ & $16(70)$ & $13(57)$ & 13 (57) & $8(35)$ & $1(4)$ \\
\hline No CIM (\%) & 198 & 134 (68) & $123(62)$ & $80(40)$ & $40(20)$ & $12(6)$ & $16(8)$ \\
\hline$P$ value & & 0.11 & 0.32 & 0.10 & $<0.01$ & $<0.01$ & 0.45 \\
\hline
\end{tabular}

IM, intestinal metaplasia of the distal stomach (antrum/fundus); CIM, gastric cardia intestinal metaplasia.

intestinal metaplasia at a normal-appearing $\mathrm{Z}$ line located in the region of the esophagogastric junction has little propensity for the development of dysplasia or adenocarcinoma (4-12). If the findings of these endoscopy studies could be applied to the general population, both the high frequency of intestinal metaplasia in short segments of columnar esophageal mucosa and its association with an increased risk of adenocarcinoma is an alarming prospect to health care providers and policy makers.

The disparity between the high frequency of intestinal metaplasia at the esophagogastric junction found in endoscopy studies and the low rate of esophageal adenocarcinoma (13), estimated at 2 to 4 per 100,000 , indicates that either the rate of in-

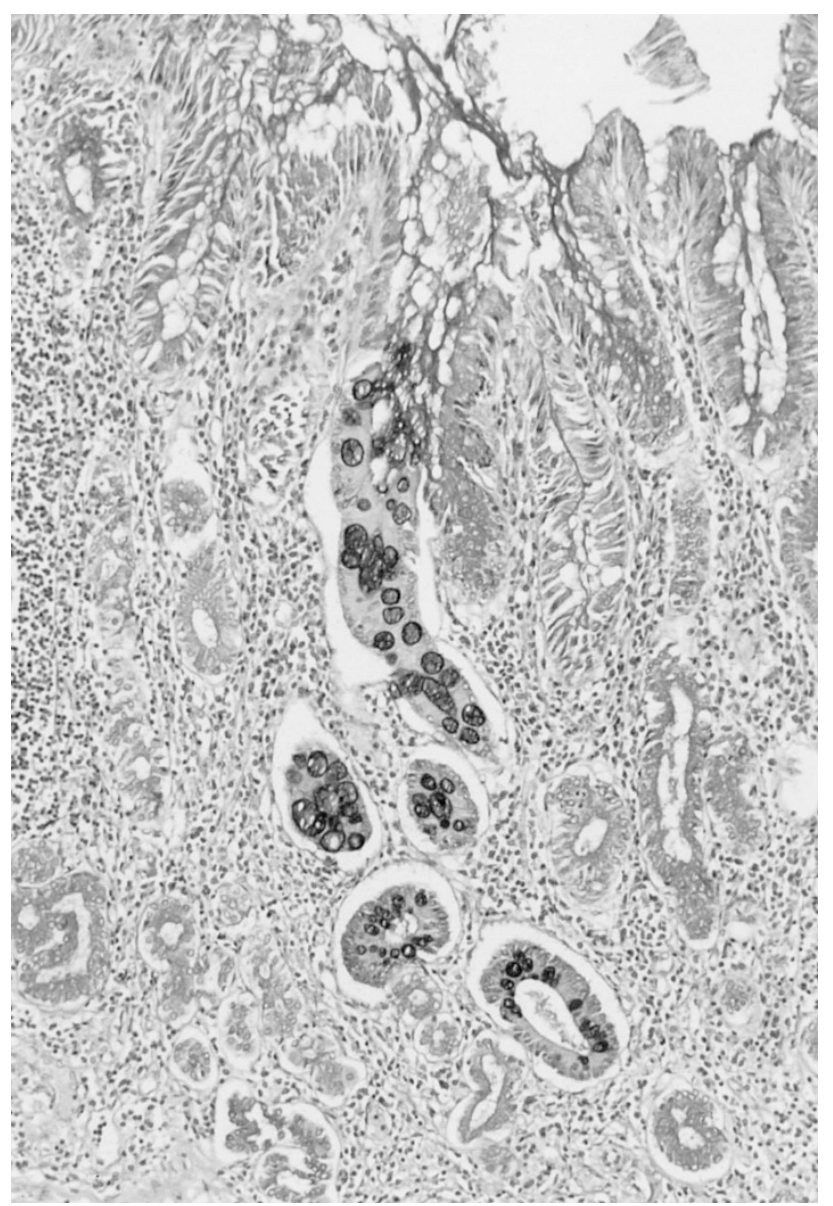

FIGURE 5. High-power magnification of gastric antrum intestinal metaplasia with Alcian blue-positive goblet cells in a background of chronic gastritis (Alcian blue/periodic acid-Schiff $\mathrm{pH} 2.5$ ). testinal metaplasia reported in these studies is not representative of the overall population or the intestinal metaplasia is more likely to be gastric in origin, where the risk of developing adenocarcinoma is not as high.

Autopsy studies offer the advantage of studying a diverse patient cohort that is representative of that seen in the general United States population (25). It also enables comprehensive histologic evaluation of the entire esophagogastric junction, thus avoiding the sampling error inherent in endoscopy studies. Furthermore, precise identification of the esophagogastric junction is possible because the location of both the gastric mucosal folds and the peritoneal reflection can be evaluated. The peritoneal reflection is a reliable anatomic landmark for the location of the esophagogastric junction and is routinely used in esophageal resection specimen mapping studies $(20,26)$. Furthermore, the absence of any dynamic esophageal movement, such as respiration or peristalsis, allows optimal localization of the esophagogastric junction, thereby eliminating many of the problems inherent in an endoscopy study.

To our knowledge, only the study by Cameron et al. (27) has attempted to evaluate the frequency of Barrett's esophagus using autopsy material. This study, however, addressed only long-segment Barrett's esophagus ( $3 \mathrm{~cm}$ or more). Moreover, only those cases considered to have long-segment Barrett's esophagus on gross inspection (a total of only 17 cases) were evaluated histologically with multiple sections. Of these 17 cases, only 7 (41\%) were found to have intestinal metaplasia on histologic evaluation. The present study, therefore, is the first to evaluate both long- and short-segment Barrett's esophagus using autopsy material. Furthermore, not only was gross inspection of the fresh specimen undertaken, but also microscopic evaluation of the entire esophagogastric junction was undertaken in all 223 patients, thereby ensuring that all possible cases of Barrett's esophagus were identified.

The results of the present study offer important insights that help explain the disparity between the high rate of intestinal metaplasia at the esophagogastric junction reported in endoscopy studies and the low incidence of esophageal adenocarcinoma. First, in an unselected patient group, the frequency of patients who had intestinal metaplasia at the 
esophagogastric junction was $11 \%$, a number that is lower than that reported in most endoscopy studies. In fact, this lower proportion was demonstrated even after the entire esophagogastric junction had been evaluated histologically using mucin histochemical stains, such as Alcian blue, which increases the sensitivity for the identification of goblet cell metaplasia (28). Second, more than $95 \%$ of patients who had intestinal metaplasia in the present study had intestinal metaplasia originating in the gastric cardia, most of whom had a normalappearing $\mathrm{Z}$ line. This contrasts to endoscopy studies, in which the majority of intestinal metaplasia (approximately two thirds in most studies) occurs in short segments of esophageal columnarappearing mucosa identified at endoscopy $(5,7,8$, 11,12 ). If the stomach, therefore, is the source of intestinal metaplasia in an asymptomatic general patient population, as the present study suggests, then a low rate of adenocarcinoma relative to a high frequency of intestinal metaplasia at the esophagogastric junction is not surprising, given the reduced likelihood of gastric intestinal metaplasia to progress to dysplasia or carcinoma (4-12).

The gastric origin of intestinal metaplasia at the esophagogastric junction seen in the majority of cases in the present study also is reflected by the demographic data and the findings in histologic sections of the distal stomach. Patients who had gastric cardia intestinal metaplasia had no preponderance for elderly white males as seen in Barrett's esophagus. In fact, no significant differences with respect to age, gender, or ethnic origin were observed when comparing patients who did and did not have gastric cardia intestinal metaplasia. In addition, gastric cardia intestinal metaplasia was associated with chronic gastritis and intestinal metaplasia of the distal stomach, both surrogate markers for $H$. pylori infection. This supports previous studies that suggested that $H$. pylori plays a role in the development of gastric cardia intestinal metaplasia $(10,29,30)$ but not in Barrett's esophagus (31-33).

The stark differences in the frequency and location of intestinal metaplasia as well as the demographic patient profile in the present study versus endoscopy studies suggest that symptomatic patients who present for endoscopy are a highly selected population with an increased predilection for Barrett's esophagus, dysplasia, and adenocarcinoma. Therefore, the data reported from endoscopy studies may not necessarily be directly applicable to the general population.

In summary, when an unselected patient population is evaluated, the proportion of cases with intestinal metaplasia at the esophagogastric junction after comprehensive assessment is only $11 \%$. Furthermore, in more than $90 \%$ of these cases, the intestinal metaplasia is located in the gastric cardia at a normal-appearing $\mathrm{Z}$ line, and not in segments of esophageal columnar-appearing mucosa. The gastric origin of intestinal metaplasia at the esophagogastric junction in the general population also is supported by the clinical and histologic profile of these patients-that is, no gender, age, or racial predilection and a high rate of chronic gastritis and distal gastric intestinal metaplasia, favoring a role for $H$. pylori infection in the development of gastric cardia intestinal metaplasia. These findings may explain the disparity between the high frequency of Barrett's esophagus reported in endoscopy studies and the very low incidence of esophageal adenocarcinoma in the general population. Health policy makers and providers should be aware that patients who present for endoscopy are a highly selected population with an increased predilection for Barrett's esophagus; therefore, data reported from endoscopy studies may not be directly applicable to the general population. Consequently, caution is warranted when applying the findings of endoscopy studies to the development of preventive and screening strategies aimed at identifying Barrett's esophagus in an asymptomatic general population.

\section{REFERENCES}

1. Haggitt RC. Barrett's esophagus, dysplasia and adenocarcinoma. Hum Pathol 1994;25:982-93.

2. Naef AP, Savary M, Ozzello L. Columnar-lined lower esophagus: an acquired lesion with malignant predisposition. J Thorac Cardiovasc Surg 1970;826-35.

3. Dent I, Bremner CO, Cohen MI. Working party report to the World Congresses of Gastroenterology, Sydney, 1990: Barrett's esophagus. J Gastroenterol Hepatol 1991;6:1-22.

4. Sharma P, Weston AP, Morales TO, Topalovski M, Mayo M, Sampliner RE. Relative risk of dysplasia for patients with intestinal metaplasia in the distal esophagus versus the gastric cardia. Gastroenterology 1999;116:A308.

5. Spechler SJ, Zeroogian JM, Antonioli DA, Wang HH, Goyal RK. Prevalence of metaplasia at the gastro-esophageal junction. Lancet 1994;344:1533-6.

6. Trudgill NJ, Suvarna SK, Kapur KC, Riley SA. Intestinal metaplasia at the squamocolumnar junction in patients attending for diagnostic gastroscopy. Gut 1997;41:585-9.

7. Chalasani N, Wo JM, Hunter JO, Waring JP. Significance of intestinal metaplasia in different areas of esophagus including esophagogastric junction. Dig Dis Sci 1997;42:603-7.

8. Johnston MI, Hammond AS, Laskin W, Jones DM. The prevalence and clinical characteristics of short segments of specialized intestinal metaplasia in the distal esophagus on routine endoscopy. Am J Gastroenterol 1996;91:1507-11.

9. Weston AP, Krmpotich P, Maksisi WF, Cherian R, Dixon A, McGregor DH, et al. Short segment Barrett's esophagus: clinical and histological features, associated endoscopic findings, and association with gastric intestinal metaplasia. Am J Gastroenterol 1996;91:981-6.

10. Morales TG, Sampliner RE, Bhattacharyya A. Intestinal metaplasia of the gastric cardia. Am J Gastroenterol 1997;92: 414-8.

11. Hackelsberger A, Gunther T, Schultze V, Manes G, DominguezMunoz JE, Roessner A, et al. Intestinal metaplasia at the gastrooesophageal junction: Helicobacter pylori gastritis or gastrooesophageal reflux disease? Gut 1998;43:17-21. 
12. Hirota WK, Loughney TM, Lazas DJ, Maydonovitch CL, Rholl V, Wong RK. Specialized intestinal metaplasia, dysplasia, and cancer of the esophagus and esophagogastric junction: prevalence and clinical data. Gastroenterology 1999;116:277-85.

13. Blot WI, Devesa SS, Kneller RW, Fraumeni IF. Rising incidence of adenocarcinoma of the esophagus and gastric cardia. JAMA 1991;265:1287-9.

14. Price AB. The Sydney System: histological division. J Gastroenterol Hepatol 1991;6:209-22.

15. Sipponen P, Hyvarian H. Role of Helicobacter pylori in the pathogenesis of gastritis, peptic ulcer and gastric cancer. Scand J Gastroenterol 1993;28:3-6.

16. Hamilton ST, Smith RR. The relationship between columnar epithelial dysplasia and invasive adenocarcinoma arising in Barrett's esophagus. Am J Clin Pathol 1987;87:301-12.

17. Hawe A, Payne WS, Weiland LH. Adenocarcinoma in the columnar epithelial lined lower (Barrett) esophagus. Thorax 1973;28:511-4

18. Haggitt RC, Tryzelaar J, Ellis FH, Colcher H. Adenocarcinoma complicating columnar epithelial-lined (Barrett's) esophagus. Am J Clin Pathol 1978;70:1-5.

19. Haggitt RC, Dean P. Adenocarcinoma in Barrett's epithelium. In: Spechler SJ, Goyal RK, editors. Barrett's esophagus: pathophysiology, diagnosis and management. New York: Elsevier; 1985. p. 153-66.

20. Hamilton SR, Smith RRL, Cameron JL. Prevalence and characteristics of Barrett's esophagus in patients with adenocarcinoma of the esophagus or esophagogastric junction. Hum Pathol 1988;19:942-8.

21. Petras RE, Sivak Mv, Rice TW. Barrett's esophagus: a review of the pathologist's role in diagnosis and management. Pathol Annu 1991;26(Pt 2):1-32.

22. Weston AP, Krmpotich PT, Cherian R, Dixon A, Topalosvki M. Prospective long-term endoscopic and histological follow-up of short segment Barrett's esophagus: comparison with traditional long segment Barrett's esophagus. Am J Gastroenterol 1997;92:407-13.

23. Drewitz DJ, Sampliner RE, Garewal HS. The incidence of adenocarcinoma in Barrett's esophagus: a prospective study of 170 patients followed 4.8 years. Am J Gastroenterol 1997;92:212-5.

24. Sharma P, Morales TH, Bhattacharyya A, Garewal HS, Sampliner RE. Dysplasia in shortsegment Barrett's esophagus: a prospective 3-year follow-up. Am J Gastroenterol 1997;92:2021-6.

25. The World Almanac and Book of Facts. New York: St. Martin's; 1996. p. 386.

26. Cameron AJ, Clifford TC, Pera M, Carpenter HA. Adenocarcinoma of the esophagogastric junction and Barrett's esophagus. Gastroenterology 1995;109:1541-6.

27. Cameron AJ, Zinsmeister AR, Ballard DJ, Carney JA. Prevalence of columnar-lined (Barrett's) esophagus: comparison of population-based clinical and autopsy findings. Gastroenterology 1990;99:918-22.

28. Nandurkar S, Talley NJ. Barrett's esophagus: the long and the short of it. Am J Gastroenterol 1999;94:30-40.

29. Goldblum JR, Vicari JJ, Falk OW, Rice TW, Peek RM, Easley K, et al. Inflammation and intestinal metaplasia of the gastric cardia: the role of gastroesophageal reflux and $\mathrm{H}$. pylori infection. Gastroenterology 1998;114:633-9.

30. Genta RM, Huberman RM, Graham DY. The gastric cardia in Helicobacter pylori infection. Hum Pathol 1994;25:915-9.

31. Abbas Z, Hussainy AS, Ibrahim F, Jafri SM, Shaildi H, Khan AH. Barrett's oesophagus and Helicobacter pylori. J Gastroenterol Hepatol 1995;10:331-3.

32. Ricaurte O, Flejou JF, Vissuzaine C, Goldfain D, Rotenberg A, Cadiot G, et al. Helicobacter pylori infection in patients with Barrett's esophagus: a prospective immunohistochemical study. J Clin Pathol 1996;49:176-7.

33. Talley NJ, Cameron M, Shorter RO, Sinsmeister AR, Phillips SF. Campylobacter pylori and Barrett's esophagus. Mayo Clin Proc 1988;63:1176-80. 